\title{
OPERATOR INEQUALITIES RELATED TO WEAK 2-POSITIVITY
}

\author{
Mohammad Sal Moslehian and Jun ICHi FujiI
}

Abstract. In this paper we introduce the notion of weak 2 -positivity and present some examples. We establish some operator Cauchy-Schwarz inequalities involving the geometric mean and give some applications. In particular, we present some operator versions of Hua's inequality by using the Choi-Davis-Jensen inequality.

Mathematics subject classification (2010): Primary 47A63; secondary 46L05, 47A30.

Keywords and phrases: Operator inequality, weakly 2-positive map, operator geometric mean, Hua's inequality, Cauchy-Schwarz inequality.

\section{REFERENCES}

[1] T. ANDO, Topics on operator inequality, Hokkaido Univ. Lecture Note, 1978.

[2] LJ. ARAmbasić, D. BAKIĆ AND M. S. Moslehian, A treatment of the Cauchy-Schwarz inequality in $C^{*}$-modules, J. Math. Anal. Appl. 381 (2011) 546-556.

[3] M.-D. CHoI, A Schwartz inequality for positive linear maps on $C^{*}$-algebras, Illinois J. Math. 18 (1974), 565-574.

[4] M.-D. CHOI, Some assorted inequalities for positive linear maps on $C^{*}$-algebras, J. Operator Theory 4 (1980), 271-285.

[5] C. Davis, A Schwartz inequality for convex operator functions, Proc. Amer. Math. Soc. 8 (1957), $42-44$.

[6] S. S. Dragomir, A survey on Cauchy-Bunyakovsky-Schwarz type discrete inequalities, J. Inequal. Pure Appl. Math., 4 (2003), no. 3, Article 63, 142 pp.

[7] R. DrNOVŠEK, An operator generalization of the Lo-Keng Hua inequality, J. Math. Anal. Appl., 196 (1995), no. 3, 1135-1138.

[8] J. I. FujII, Operator inequalities for Schwarz and Hua, Sci. Math. 2 (1999), no. 3, 263-268.

[9] J. I. FUJII, Operator-valued inner product and operator inequalities, Banach J. Math. Anal. 2 (2008), no. 2, 59-67.

[10] M. Fujil, S. Izumino, R. NAKamoto And Y. Seo, Operator inequalities related to CauchySchwarz and Holder-McCarthy inequalities, Nihonkai Math. J. 8 (1997) 117-122.

[11] T. Furuta, J. Mićić Hot, J. PeČArić And Y. SeO, Mond-Pečarić Method in Operator Inequalities, Element, Zagreb, 2005.

[12] F. Hansen and G. K. Pedersen, Jensen's operator inequality, Bull. London Math. Soc. 35 (2003), no. $4,553-564$.

[13] D. ILIŠEVIĆ AND S. VARošAneC, On the Cauchy-Schwarz inequality and its reverse in semi-inner product $C^{*}$-modules, Banach J. Math. Anal. 1 (2007), 78-84.

[14] D. R. Jocić, Cauchy-Schwarz and means inequalities for elementary operators into norm ideals, Proc. Amer. Math. Soc. 126 (1998), no. 9, 2705-2711.

[15] M. JoIŢA, On the Cauchy-Schwarz inequality in $C^{*}$-algebras, Math. Rep. (Bucur.) 3 (53) (2001), no. 3, 243-246.

[16] F. KitTaneH, Some norm inequalities for operators, Canad. Math. Bull. 42 (1999), no. 1, 87-96.

[17] M. S. Moslehian, Operator extensions of Hua's inequality, Linear Algebra Appl. 430 (2009), no. 4, 1131-1139.

[18] M. S. Moslehian And L.-E. Persson, Reverse Cauchy-Schwarz inequalities for positive $C^{*}$ valued sesquilinear forms, Math. Inequal. Appl. 12 (2009), no. 4, 701-709. 
[19] S. RADAS AND T. ŠIKIć, A note on the generalization of Hua's inequality, Tamkang J. Math., 28 (1997), no. 4, 321-323.

[20] K. Tanahashi, A. Uchiyama and M. Uchiyama, On Schwarz type inequalities, Proc. Amer. Math. Soc. 131 (2003), no. 8, 2549-2552.

[21] S. WADA, On some refinement of the Cauchy-Schwarz inequality, Linear Algebra Appl. 420 (2007), no. $2-3,433-440$. 